\title{
Analysis of the Factors Influencing Functional Outcomes in Patients with Spinal Cord Injury
}

\author{
Sasa Milicevic $\left.{ }^{1}\right)^{*}$, Vladimir Piscevic ${ }^{2}$, Zoran Bukumiric ${ }^{3)}$, Aleksandra Karadzov Nikolic ${ }^{4}$, \\ Aleksandra Sekulic ${ }^{1)}$, Aleksandar Corac ${ }^{5}$, Rade Babovic $^{1}$, Slobodan Jankovic ${ }^{6}$ ) \\ 1) Clinic for Rehabilitation "Dr M. Zotovic”: Sokobanjska 13, Belgrade, Serbia \\ 2) Department of PRM, KBC Zvezdara, Serbia \\ 3) Medical Faculty in Belgrade, Institute of Medical Statistics and Informatics, Serbia \\ 4) Special Hospital of Cerebral Palsy and Developmental Neurology, Serbia \\ 5) Medical Faculty Pristina, Department of Preventive Medicine, Serbia \\ 6) Medical Faculty in Kragujevac, Institute of Pharmacology, Serbia
}

\begin{abstract}
Purpose] The extent of functional independence ultimately achieved by an individual patient will be influenced by a variety of medical and non-medical factors. [Subjects and Methods] this study included 419 patients with spinal cord lesions treated in the Clinic for Rehabilitation "Dr M. Zotovic", Belgrade, Serbia, from January 2000 to December 2009. The patients were divided in two groups according to achievement of increase in Functional Independence Measure (FIM) score of more than 13 at discharge compared to admission. A variety of clinical variables were followed in both groups. [Results] one hundred twenty-one patients (28.9\%) showed improvements in FIM score of $\leq 13$, while 298 (71.1\%) patients showed an increases in FIM score of $>13$ at discharge compared to admission. Better functional recovery was observed in patients with non-traumatic spinal cord lesions, lower neurological levels of the lesion $(\mathrm{OR}=6.07)$, and in patients treated surgically, but the level of the spinal cord lesion was the most influential factor affecting outcome. [Conclusion] the patients with spinal cord lesions should not only be grouped by traumatic and non-traumatic lesions only, but also sub-categorized, according to the etiology, level of injury and treatment method.
\end{abstract}

Key words: Spinal cord lesions, Rehabilitation, Functional outcomes

(This article was submitted Jul. 2, 2013, and was accepted Aug. 4, 2013)

\section{INTRODUCTION}

Patients with spinal cord injuries (SCI) are confronted with motor and sensory deficits and dysfunction of the bladder and bowel, resulting in disabilities in daily activities. Medical care of patients with SCI imposes a great burden on any health-care system. The causes of the SCI include trauma, vascular disorders, tumors of both malignant and benign etiology, infections, and developmental disorders ${ }^{1)}$. The incidence of SCI ranges globally from 10.4 to 83 cases per million per year, ${ }^{1,2)}$. The incidence of SCI in Serbia is unknown, because there is no registry of patients with these injuries in our country. The aim of rehabilitation is to treat patients with SCI in order to achieve optimal independence and a satisfactory quality of life in their own community ${ }^{2}$. Fortunately, most patients return home after rehabilitation with significant degrees of functional independence ${ }^{3,4)}$. The extent of the functional independence ultimately achieved

*Corresponding author. Sasa Milicevic (e-mail: rsmilicevic@, gmail.com)

(C)2014 The Society of Physical Therapy Science

This is an open-access article distributed under the terms of the Creative Commons Attribution Non-Commercial No Derivatives (by-ncnd) License $<$ http://creativecommons.org/licenses/by-nc-nd/3.0/>. by an individual patient will also be influenced by a variety of medical and non-medical factors, such as age, body mass index, associated injuries, severity of spasticity, motivation, family support, living environment, pre-morbid lifestyle, vocation, educational background, financial status, etc ${ }^{5)}$. This study deals only with medical factors: neurological deficit, level of a spinal cord injury, type and cause of injury, methods of treatment, secondary complications, associated injuries, age and gender.

The result of this study emphasize the great need for more precise knowledge about prognosis of functional outcomes and increased precision would enable better planning of a rehabilitation tailored to the needs of the patient.

\section{SUBJECTS AND METHODS}

This study was designed as a retrospective, case-control study. The patients included in the study had an SCI, and were admitted to the Clinic for Rehabilitation"Dr M. Zotovic", Belgrade, Serbia, from January 2000 to December 2009. The factors that were tested for their influence on the functional outcomes of the patients with spinal cord injury included: neurological deficit, i.e. neurological level of injury, type and cause of injury, methods of treatment, secondary complications, associated injuries, age and gender. The data were obtained from history and other available medical 
records of patients.

This study included 419 patients who were diagnosed with SCI at the institutions that were responsible for the primary care of these patients. The Patients with any kind of deterioration from the original condition that resulted in termination of rehabilitation, the those younger than 18 years, and those with an injury below the $\mathrm{L}_{1}$ level the spinal cord were excluded from the study.

During hospitalization the patients were assessed using tests aimed at measuring the degree of their functional recovery and presence of neurological sequelae after spinal injury: the FIM test (Functional independence measure), the ASIA scale (American Spinal Injury Association impairment scale) used, and the MAS score (Modified Ashworth score).

The Functional status was assessed by the Functional Independence Measure (FIM). The FIM is one of the most widely used instruments for assessing the functional outcome of various rehabilitation programs ${ }^{6,7)}$. Admission FIM scores (taken at the beginning of rehabilitation), discharge FIM scores (taken at the end of rehabilitation just before discharge) were noted and the differences of the two scores were calculated ${ }^{8)}$. All patients received a comprehensive rehabilitation program, which included medical and nursing care, physical therapy and occupational therapy.

The subjects were retrospectively divided in two groups: the first group consisted of patients who had an increase in FIM scores of more than 13 at discharge compared to admission, and the second group was made up of subjects whose FIM score had not increases by 13 on discharge compared to admission ${ }^{2)}$.

The international standards of the American Spinal Injury Association (ASIA) were used to record motor and sensory levels of injury ${ }^{9}$. Completeness of the lesion was recorded according to the ASIA Impairment Scale (AIS). The AIS grades A is defined as complete motor lesions, and AIS grades $\mathrm{B}, \mathrm{C}$ and $\mathrm{D}$ are defined as incomplete motor lesions ${ }^{10)}$.

To determine the level of spasticity, we used the MAS test (Modified Ashworth Score) ${ }^{11)}$.

Recordings were made at the time of admission to the rehabilitation department as well as at discharge.

For the analysis of primary data descriptive statistical methods were used, as well as statistical hypothesis testing methods, and methods for analysis of the relationship between potential predictors and outcomes. Among the descriptive statistical methods, we have used the central tendency (arithmetic mean), measures of variability (standard deviation) and relative numbers. To test our hypothesis about the difference in frequency, $\chi^{2}$ test was used. The ttest and Mann-Whitney test were used to testing the hypothesis about the difference of arithmetic means. Analysis of relations between binary outcomes and potential predictors was made using logistic regression.

Statistical hypotheses were tested the 0.05 level of statistical significance.

\section{RESULTS}

The study included 419 patients. The average value of the difference of FIM scores on discharge compared to admission for all patients was $22.5 \pm 13.07$. The minimum difference of FIM scores was to -1 , the maximum was 55 . Significant functional improvement was defined as a change in discharge-admission FIM score greater than 13, and we used it to divide patients into two groups: those with a FIM score increased of $>13$, or $\leq 13$. Out of the total number of patients during the rehabilitated, $121(28.9 \%)$ had improvements in FIM score of $\leq 13$, and 298 (71.1\%) patients had an increase in FIM score of $>13$ at discharge compared to admission.

The average age of the patients in the study was $45.5 \pm$ 16.8 years. The youngest patient was 18 years old and the oldest 83 years. The mean age in the FIM $\leq 13$ group was $45.3 \pm 17.5$ years, and that of the FIM $>13$ group, it was 45.6 \pm 16.5 years. There was no statistically significant difference in age between the groups $(p=0.85)$.

Out of the total number of patients, $310(74 \%)$ were males and $109(26 \%)$ were females. Women were more likely to show increases in FIM scores of more than 13 at discharge compared to admission than men $(73.4 \%$ vs. $70.3 \%)$, but this difference was not statistically significant $(\mathrm{p}=0.543)$.

Based on the etiology of the injury, the patients were divided into two groups: 269 patients had traumatic and 150 patients had non-traumatic spinal cord injury. One hundred eighty-two (67.7\%) patients with traumatic and $116(77.3 \%)$ patients with non-traumatic causes of injury, showed an increases in FIM score of $>13$ at discharge compared to admission. Patients with non-traumatic spinal cord injuries tended to have more frequently show an improvement in of FIM score of more than 13 points $(\mathrm{p}=0.036)$.

Associated injuries were present in 107 (25.5\%) patients, while $312(74.5 \%)$ patients did not have them. A FIM score improvement of $>13$ was recorded for 71 patients with associated injuries, and for 227 patients without them, but this difference was not statistically significant $(p=0.207)$.

Complications before rehabilitation were experienced by $84(20 \%)$ patients, while none were experienced by 335 $(80 \%)$ of them. For 242 patients without complications were not registered before the rehabilitation and 56 patients with complications the FIM score increased by more than 13 points during rehabilitation. There was no statistically significant difference in the frequency of occurrence of complications before rehabilitation between the groups ( $p$ $=0.314$ ).

The Patients were treated surgically and conservatively: of the total number of patients, $260(62.1 \%)$ was treated surgically and 159 (37.9\%) conservatively. Two hundred four (78.5\%) surgically treated patients and 94 (59.1\%) conservatively treated patients showed improvements in FIM score of $>13$ during rehabilitation. Surgically treated patients were statistically more likely to show improvements in FIM score of $>13$ during rehabilitation $(\mathrm{p}<0.001)$.

Of the total number of patients, $236(56.3 \%)$ had an incomplete lesion, while $183(43.7 \%)$ had a complete spinal cord lesion. In 163 patients with incomplete and in 135 patients with complete lesions there was an increase in FIM score of $>13$; however, this difference was not statistically significant $(\mathrm{p}=0.292)$.

Among the patients on admission, according to the Com- 
pleteness of the lesion on admission, the predominant lesion was determined as ASIA A lesions (43.2\%), followed by ASIA C (36.3\%) and ASIA B (20.5\%). We recorded FIM score improvements of $>13$ for 134 (74\%) patients with ASIA A, 63 (73.3\%) ASIA B patients, and 101 (66.4\%) patients with ASIA C lesions. There was no statistically significant difference in the frequency of the completeness of lesions in relation to the increase in FIM $>13$ at discharge compared to admission $(\mathrm{p}=0.279)$.

Based on the level of lesion, the patients were divided into three groups: patients with cervical, thoracic and lumbar spinal cord injury. One hundred seventy-four (41.5\%) patients had cervical injury, 182 (43.4\%) had thoracic injury, and $63(15 \%)$ patients had lumbar injury. Depending on the level of injury, the improvement of FIM score of $>13$ during rehabilitation was showed by $78(44.8 \%)$ patients with cervical injuries, $161(88.5 \%)$ patients with thoracic injuries and $59(93.7 \%)$ patients with lumbar spinal cord injury, which a was statistically significant difference $(\mathrm{p}<0.001)$. Functional recovery was better in patients with lower levels of neurological lesions (thoracic and lumbar).

On admission, the Ashworth median score of all patients was to 0 (range: $0-4$ ). Ashworth median score on admission for patients who showed improved FIM scores of $\leq 13$ was 0 (range: $0-3$ ), and it was not significantly different from that of patients with improvements in FIM score of $>13$ (median $=0$, range: $0-4)(\mathrm{p}=0.409)$.

Spasticity as a complication during rehabilitation occurred in 249 (59.4\%) patients, while 170 (40.6\%) had no spasticity during the rehabilitation. Increase in FIM score of $>13$ at discharge compared to admission was showed by $160(64.3 \%)$ patients with spasticity, and by $138(81.2 \%)$ patients without spasticity. Spasticity during rehabilitation was associated with worse functional recovery of patients $(\mathrm{p}<0.001)$.

The average value of FIM score at admission for all patients was $80.09 \pm 11.85$. The minimum value of FIM score at admission was 43 and the maximum 114. The average value of FIM score at admission of patients who showed an increased in FIM score of $\leq 13$ score was $76.01 \pm 15.09$, while that of patients who showed an increased of FIM score of $>13$ was $81.74 \pm 9.8$. There was a statistically significant difference in the value of FIM scores at admission between these groups of patients $(p<0.001)$.

The average value of FIM score at discharge for all patients was $102.59 \pm 17.45$. The minimum value of FIM score at discharge was 43 and the maximum 126. The average value of FIM score at discharge of patients with increase of FIM scores of $\leq 13$ was $82.23 \pm 17.05$, while that of patients with increase of FIM score of $>13$ it was $110.86 \pm 8.58$. There was a statistically significant difference in the value of FIM score at discharge between the groups $(p<0.001)$.

The average duration of rehabilitation for all patients was $162.22 \pm 90.31$ days. The average duration of rehabilitation for patients with increase of FIM score of $\leq 13$ was $171.27 \pm$ 101.81 days, and that of patients with increase of FIM score of $>13$ was $158.53 \pm 85.08$ days. However, this difference in duration of rehabilitation of patients was not statistically significant $(p=0.315)$.

In a simple logistic regression model statistically sig- nificant predictors of FIM scores increase of more than 13 were: etiology (method of injury) $(B=0489, p=0.037$ ), neurological level of lesion $(B=1939, p<0.001)$ and the value of FIM score on admission $(B=0044, p<0.001)$.

In the simple logistic regression model, as the statistically significant predictors that will not of in FIM scores increases over 13 were: method of treatment (conservative compared to the surgical treatment) $(B=-0924, p<0.001)$, and spasticity as a complications during rehabilitation $(\mathrm{B}=$ $-0875, \mathrm{p}<0.001)$.

The multiple logistic regression model included those predictors that were statistically significant in the simple logistic regression model at the level of 0.1 . The model contained five predictors listed in Table 2, which were compared among 419 patients. The whole model (all predictors) was statistically significant $\left(\chi^{2}=110.428 ; \mathrm{DF}=5 ; \mathrm{p}<0.001\right)$.

In the multiple logistic regression model, the statistically significant predictor of a FIM score increase of more than 13 was neurological level of injury $(B=1.804 ; p<0.001)$, and it's odds ratio was $\mathrm{OR}=6.07$. This suggests that patients with lower neurological level of lesion (thoracic and lumbar compared to cervical) are 6 times more likely, by category of the lesion level, to increase their FIM score by over 13, with control of all other factors in the model.

In the multiple logistic regression model, method of treatment (surgical or conservative) and FIM score on admission came very close to significance $(\mathrm{p}=0.054$ and $\mathrm{p}=$ 0.064 respectively). These two predictors should be checked and explored in the future primarily by increasing the sample to be tested.

\section{DISCUSSION}

All patients who participated in the study had been admitted to the branch hospitals where only physical therapy and rehabilitation patients are treated and followed. Acute treatments of these patients were completed and they were medically stabilized. Measurement of functional outcomes for patients with spinal cord injury is an integral part of any goal-orientated, multidisciplinary rehabilitation program and it requires suitable assessment tools. In our study the standard, validated assessment tools of functional outcomes have showed that more significant improvements could be expected in traumatic and paraplegic lesions. In addition, the mean FIM scores increased as the level of injury descended from the cervical to the thoracic and lumbar regions. In our study with an odds ratio of $\mathrm{OR}=$ 6.07 , indicating the patients with lower neurological level of lesion (thoracic and lumbar compared to cervical) are 6 times more likely, by category of the lesion level, to show an increase FIM score of over 13, with control of all other factors in the model. Our results only partially agree with the results of the study conducted by Scivoletto et al. of 247 patients with spinal cord lesions. In their study the patients with traumatic and ischemic spinal cord lesions did not differ in the extent of neurological and functional recovery; however, the outcomes of these patients were better if the level of spinal injury was lower, as in our study ${ }^{12}$. Another study by Scivoletto et al. have showed that patients with traumatic or inflammatory spinal cord lesions had similar 
Table 1. Simple logistic regression model

\begin{tabular}{|c|c|c|}
\hline & $\begin{array}{l}\text { FIM change } \leq 13 \\
\qquad(\mathrm{n}=121)\end{array}$ & $\begin{array}{c}\text { FIM change }>13 \\
\qquad(n=298)\end{array}$ \\
\hline Age, $\bar{x} \pm \mathrm{SD}$ & $45.3 \pm 17.5$ & $45.6 \pm 16.5$ \\
\hline \multicolumn{3}{|l|}{ Gender, n (\%) } \\
\hline male & $92(76 \%)$ & $218(73.2 \%)$ \\
\hline female & $29(24 \%)$ & $80(26.8 \%)$ \\
\hline \multicolumn{3}{|l|}{ Etiology of injury, n (\%) } \\
\hline traumatic & $87(71.9 \%)$ & $182(61.1 \%)$ \\
\hline non-traumatic & $34(28.1 \%)$ & $116(38.9 \%)$ \\
\hline \multicolumn{3}{|l|}{ Associated injuries, n (\%) } \\
\hline no & $85(70.2 \%)$ & $227(76.2 \%)$ \\
\hline yes & $36(29.8 \%)$ & $71(23.8 \%)$ \\
\hline \multicolumn{3}{|l|}{ Complications before rehabilitation, $\mathrm{n}(\%)$} \\
\hline no & $93(76.9 \%)$ & $242(81.2 \%)$ \\
\hline yes & $28(23.1 \%)$ & $56(18.8 \%)$ \\
\hline \multicolumn{3}{|l|}{ Methods of treatment, n (\%) } \\
\hline operative & $56(46.3 \%)$ & $204(68.5 \%)$ \\
\hline conservative & $65(53.7 \%)$ & $94(31.5 \%)$ \\
\hline \multicolumn{3}{|l|}{ Completeness of lesion, $\mathrm{n}(\%)$} \\
\hline incomplete & $73(60.3 \%)$ & $163(54.7)$ \\
\hline complete & $48(39.7 \%)$ & $135(45.3 \%)$ \\
\hline \multicolumn{3}{|l|}{ ASIA scale on admission, $\mathrm{n}(\%)$} \\
\hline A & $47(38.8 \%)$ & $134(45 \%)$ \\
\hline B & $23(19 \%)$ & $63(21.1 \%)$ \\
\hline $\mathrm{C}$ & $51(42.1 \%)$ & $101(33.9 \%)$ \\
\hline \multicolumn{3}{|l|}{ Level of injury, $n(\%)$} \\
\hline cervical & $96(79.3 \%)$ & $78(26.2 \%)$ \\
\hline thoracic & $21(17.4 \%)$ & $161(54 \%)$ \\
\hline lumbar & $4(3.3 \%)$ & $59(19.8 \%)$ \\
\hline Modified Ashworth scale, median (range) & $0(0$ to 3$)$ & $0(0$ to 4$)$ \\
\hline \multicolumn{3}{|c|}{ Complications during rehabilitation - spasticity, n (\%) } \\
\hline no & $32(26.4 \%)$ & $138(46.3 \%)$ \\
\hline yes & $89(73.6 \%)$ & $160(53.7 \%)$ \\
\hline FIM score on admission, $\bar{x} \pm \mathrm{SD}$ & $76.01 \pm 15.09$ & $81.74 \pm 9.8$ \\
\hline Length of stay, $\bar{x} \pm \mathrm{SD}$ & $171.27 \pm 101.81$ & $158.53 \pm 85.08$ \\
\hline
\end{tabular}

Table 2. Multiple logistic regression with an increase of FIM score over 13 for rehabilitation as the dependent variable

\begin{tabular}{|c|c|c|c|c|c|}
\hline \multirow{2}{*}{ Independent variable } & \multirow{2}{*}{$\mathrm{B}$} & \multirow{2}{*}{$\mathrm{p}$} & \multirow{2}{*}{ OR } & \multicolumn{2}{|c|}{$95 \%$ confidence interval } \\
\hline & & & & lower limit & upper limit \\
\hline Etiology of injury & 0.17 & 0.562 & 1.19 & 0.67 & 2.11 \\
\hline Methods of treatment & -0.486 & 0.054 & 0.61 & 0.37 & 1.01 \\
\hline Neurological level of lesion & 1.804 & $<0.001$ & 6.07 & 3.66 & 10.08 \\
\hline Complications during rehabilitation - spasticity & 0.068 & 0.816 & 1.07 & 0.6 & 1.9 \\
\hline FIM score on admission & 0.021 & 0.064 & 1.02 & 0.99 & 1.04 \\
\hline
\end{tabular}

functional outcomes after recovery, stressing once more that the level and extent of spinal cord lesions are the most important predictors of functional recovery, rather than the etiology of the lesions ${ }^{13)}$.

The length of stay in our study appeared to be much lon- ger than in other studies. The length of stay was remarkably long in patients whose FIM scores increased by $\leq 13$ (171.27 \pm 101.81 days), and much longer that of patients whose FIM score increased by $>13(158.53 \pm 85.08$ days $)$. This could be explained by there being a larger proportion of patients 
with non-traumatic spinal cord lesions in the group with FIM score increase of $>13$, since it was previously shown that non-traumatic spinal cord lesions were associated with shorter rehabilitation length of stay ${ }^{14)}$. However, the overall long length of stay in our study could be explained by the extensive time required in Serbian circumstances for three crucial processes of SCI rehabilitation: associated injury, secondary complication during the rehabilitation, and home modification.

Gender difference was not found between the groups, but overall there were more men in our study. Considering that there were more patients with traumatic than non-traumatic spinal cord lesions in our study, and that traumatic spinal cord lesions are more frequent among men, the predominance of males was not a surprise. The age of our patients did not influence functional outcome, and this is not in accordance with other studies, which have shown that patients with spinal cord lesions and advanced age are less active after recovery ${ }^{15}$. This disagreement may be partially explained by the fact that our patients were generally younger those of other studies (Table 1).

In our study surgical treatment of spinal injuries was associated with better functional outcome, which was not the case with other series of patients ${ }^{16,17)}$, where only lack of neurological deterioration after surgery was demonstrated. However, the majority of authors agree that the true efficacy of surgical treatment of spinal injuries in regard to neurological recovery can only be established by means of a large and well designed randomized controlled clinical trial ${ }^{17)}$.

In conclusion, based on the associations of etiology, level and treatment method of spinal cord lesions with functional outcome observed in our study, the patients with spinal cord lesions should not be grouped by traumatic and non-traumatic lesions only, but also sub-categorized, according to etiology, level of injury and treatment method. This categorization would make the planning of the rehabilitation program, definition of targets of the therapy and the estimation of the results of the therapy more efficient.

\section{REFERENCES}

1) Wyndaele M, Wyndaele JJ: Incidence, prevalence and epidemiology of spinal cord injury: what learns a worldwide literature survey? Spinal Cord,
2006, 44: 523-529. [Medline] [CrossRef]

2) Tang V, Harvey D, Park Dorsay J, et al.: Prognostic indicators in metastatic spinal cord compression: using functional independence measure and Tokuhashi scale to optimize rehabilitation planning. Spinal Cord, 2007, 45: 671-677. [Medline] [CrossRef]

3) Scivoletto G, Frachi S, Laurenza L: Traumatic and non-traumatic spinal cord lesions: an Italian comparison of neurological and functional otucomes. Spinal Cord, 2011, 49: 391-396. [Medline] [CrossRef]

4) Osterthun R, Post MW: Asbeck van FWA: Characteristics, length of stay and functional outcome of patients with spinal cord injury in Dutch and Flemish rehabilitation centres. Spinal Cord, 2009, 47: 339-344. [Medline] [CrossRef]

5) Gupta A, Taly AB, Srivastava A, et al.: Traumatic vs non-traumatic spinal cord lesions: comparison of neurological and functional outcome after inpatient rehabilitation. Spinal Cord, 2008, 46: 482-487. [Medline] [CrossRef]

6) Uniform Data System for Medical Rehabilitation. Guide for the Uniform Data Set for Medical Rehabilitation (including the FIMt Instrument), version 5.1. Buffalo, State University of New York: 1997.

7) Heinemann $\mathrm{AW}$, Linacre JM, Wright BD, et al.: Relationships between impairment and physical disability as measured by the Functional Independence Measure. Arch Phys Med Rehabil, 1993, 74: 566-573. [Medline] [CrossRef]

8) Dodds TA, Matrin DP, Stolov WC, et al.: A validation of the Functional Independence Measurement and its performance among rehabilitation inpatients. Arch Phys Med Rehabil, 1993, 74: 531-536. [Medline] [CrossRef]

9) American Spinal Injury Association/International Medical Society of Paraplegia (ASIA/IMSOP): International Standards for Neurological and Functional Classification of Spinal Cord Injury (Revised edition). Chicago, American Spinal Injury Association: 2000.

10) Kirshblum SC, Memmo P, Kim N, et al.: Comparison of the revised 2000 American Spinal Injury Association Classification Standards with the 1996 Guidelines. Arch Phys Med Rehabil, 2002, 81: 502-505. [CrossRef]

11) Bohannon RW, Smith MB: Interrater reliability of a modified Ashworth scale of muscle spasticity. Phys Ther, 1987, 67: 206-207. [Medline]

12) Scivoletto G, Laurenza L, Mammone A, et al.: Recovery following ischemic myelopathies and traumatic spinal cord lesions. Spinal Cord, 2011, 49: 897-902. [Medline] [CrossRef]

13) Scivoletto G, Cosentino E, Mammone A, et al.: Inflammatory myelopathies and traumatic spinal cord lesions: comparison of functional and neurological outcomes. Phys Ther, 2008, 88: 471-484. [Medline] [CrossRef]

14) McKinley WO, Seel RT, Gadi RK, et al.: Nontraumatic vs. traumatic spinal cord injury: a rehabilitation outcome comparison. Am J Phys Med Rehabil, 2001, 80: 693-699. [Medline] [CrossRef]

15) Pentland W, McColl MA, Rosenthal C: The effect of aging and duration of disability on long term health outcomes following spinal cord injury. Paraplegia, 1995, 33: 367-373. [Medline] [CrossRef]

16) Marré B, Ballesteros V, Martínez C, et al.: Thoracic spine fractures: injury profile and outcomes of a surgically treated cohort. Eur Spine J, 2011, 20: 1427-1433. [Medline] [CrossRef]

17) Reinhold M, Knop C, Beisse R, et al.: Operative treatment of 733 patients with acute thoracolumbar spinal injuries: comprehensive results from the second, prospective, internet-based multicenter study of the Spine Study Group of the German Association of Trauma Surgery. Eur Spine J, 2010, 19: 1657-1676. [Medline] [CrossRef] 